\title{
Publisher Correction: Current status and future directions of multivalent metal-ion batteries
}

Yanliang Liang (D), Hui Dong (D), Doron Aurbach (D) and Yan Yao (D)

Correction to: Nature Energy https://doi.org/10.1038/s41560-020-0655-0, published online 16 July 2020.

In the version of this Review Article originally published, in Fig. 3a bottom inset, the labels for the left and right double-headed arrows were switched; the left arrow should have been labelled ' $Q_{\text {plating }}$ ' and the right arrow ' $Q_{\text {switching. }}$. In addition, the equation ' $\eta=Q_{\text {plating }} / Q_{\text {stripping }}$ ' was incorrect and should have read ' $\eta=Q_{\text {stripping }} / Q_{\text {plating. }}$ '. All versions of the Review Article have been amended.

Published online: 30 July 2020

https://doi.org/10.1038/s41560-020-0676-8

(c) Springer Nature Limited 2020 